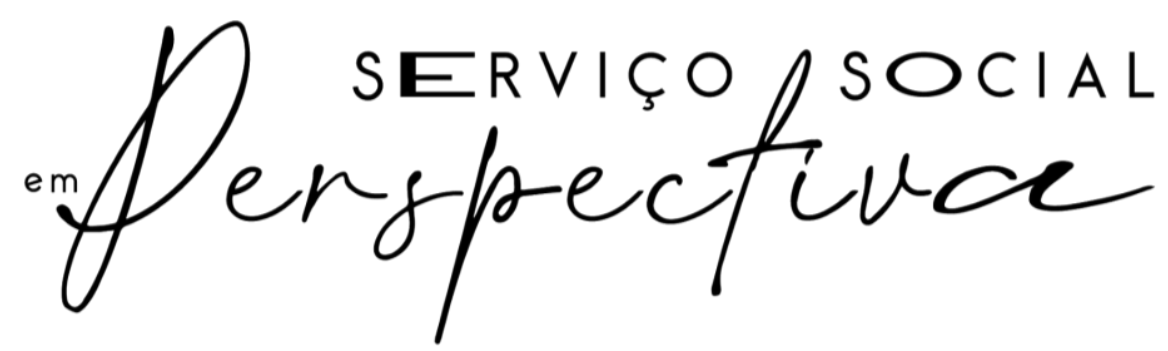

Montes Claros (MG), volume 5, número 2, jul./dez. 2021. I ISSN 2527-1849

\title{
EFEITOS DA PRECARIZAÇÃO EM MARCHA NO ENSINO SUPERIOR BRASILEIRO NA FORMAÇÃO PROFISSIONAL EM SERVIÇO SOCIAL
}

\section{EFECTOS DE LA MARCHA PRIMARIA EN LA EDUCACIÓN SUPERIOR BRASILEÑA SOBRE LA FORMACIÓN PROFESIONAL EN EL TRABAJO SOCIAL}

Elaine Cristina da Silva'

\begin{abstract}
Resumo: Este ensaio bibliográfico busca refletir sobre o cenário histórico de desmonte das universidades brasileiras, acentuado pela crise sanitária global de Covid-19. e como isso impacta na formação profissional em Serviço Social. Contextualiza como a universidade pública passa a ser utilizada para fins privados, é submetida à lógica empresarial e do mercado financeiro, sendo fortemente descaracterizada e flexibilizada. Esta. perde sua autonomia. tendo, muitas vezes, que adaptar seus curriculos de graduação e pós-graduação às demandas do capital. Sua qualidade de ensino, pesquisa e extensão é tensionada e atingida por critérios de produtividade e rentabilidade econômica. A crise sanitária atual expõe a crise na educação superior e desmascara os ditames do capital. Apesar de desafiador, é preciso acreditar que esta mesma universidade sucateada também pode ser o palco da construção do conhecimento crítico, de resistência, denúncia, de luta, de possibilidades. A pesquisa e a investigação que não estão subordinadas aos interesses do capital possibilitam uma nova postura diante da realidade apresentada e uma nova forma de olhar a universidade considerando-a. apesar de todos os seus problemas, um espaço onde é possivel geminar o conhecimento. Utilizar a pesquisa, sobretudo, como estratégia de resistência ao sistema que está imposto, como atitude combativa, reafirmando a luta por uma universidade pública de qualidade, aliado ao projeto ético-político profissional, rompendo com o aligeiramento do ensino, retomando sua qualificação, de maneira a preservar a essência da universidade que é a construção e reconstrução do conhecimento.
\end{abstract}

Palavras-chave: Desmontes. Universidade. Formação Profissional. Pesquisa.

Resumen: Este ensayo bibliográfico busca reflexionar sobre el escenario histórico de desmantelamiento de las universidades brasileñas, acentuado por la crisis de salud global en Covid-19. y cómo impacta en la formación profesional en Trabajo Social. Contextualiza cómo la universidad pública comienza a ser utilizada para fines privados, se somete a la lógica empresarial y del mercado financiero, quedando fuertemente descalificada y flexibilizada. Este último pierde su autonomía, teniendo que adaptar a menudo sus planes de estudios de pregrado y posgrado a las demandas del capital. Su calidad de enseñanza, investigación y extensión se ve tensa y afectada por criterios de productividad y rentabilidad económica.

\footnotetext{
1 Assistente Social do Colégio de Aplicação - UFSC. Graduada em Serviço Social pela Universidade Federal de Santa Catarina (2009). Mestre em Serviço Social pelo Programa de Pós-Graduação em Serviço Social da Universidade Federal de Santa Catarina (2012). E-mail: elaine.assistentesocial@gmail.com
}

Artigo submetido em: 18 de março de 2021.

Artigo aceito em: 22 de maio de 2021.

p. 10-33, DOI: https://doi.org/10.46551/rssp202117 
SILVA, E. C.

Efeitos da precarização em marcha no ensino superior brasileiro e os reflexos na formação profissional em Serviço Social

La actual crisis de salud expone la crisis de la educación superior y desenmascara los dictados del capital. A pesar de ser desafiante, es necesario creer que esta misma universidad desguazada también puede ser el escenario para la construcción de saberes críticos. resistencias, denuncias, luchas, posibilidades. La investigación y la investigación que no se subordinan a los intereses del capital posibilitan una nueva actitud ante la realidad presentada y una nueva forma de ver la universidad, considerándola, a pesar de todos sus problemas. un espacio donde es posible hermanar el conocimiento. Utilizar la investigación, sobre todo. como estrategia de resistencia al sistema que se impone. como actitud combativa. reafirmando la lucha por una universidad pública de calidad, aliada al proyecto ético-político profesional, rompiendo con el aligeramiento de la docencia, retomando su calificación, de manera de preservar la esencia de la universidad que es la construcción y reconstrucción del conocimiento.

Palavras-chave em segundo idioma: Desmontar. Universidad. Formación profesional. Buscar.

INTRODUÇÃO

Não é possivel pensar na formação profissional do Serviço Social dissociado do espaço que possibilita e concretiza a construção do conhecimento: a universidade. Falar de diretrizes curriculares, de ensino, de formação e exercício profissional e de produção do conhecimento sem mencionar o quadro em que se situa a universidade é não considerar a totalidade, e as singularidades que compõem o quadro do ensino superior no Brasil. Realizar este trânsito, esta mediação, portanto, é fundamental para compreender os impasses, dificuldades e limites que impossibilitam a efetivação de uma educação emancipatória.

Desta forma, faz-se fundamental compreender a universidade como espaço de vitalidade, de vivências, troca de experiências, construção do saber, mas sobretudo, reconhecer a educação como estratégia de luta de classes. A universidade brasileira. mais especificamente a universidade pública, tem sofrido grandes reformas em seu interior que põe em xeque a sua finalidade última de proposição, busca, construção e efetividade do conhecimento. A compreensão destes elementos políticos e conjunturais são estruturantes para se discutir a formação dos assistentes sociais e compreender o caráter que se quer imprimir a profissão. Portanto, compreender o cenário histórico de desmonte das universidades públicas, acentuado pela crise sanitária global de Covid-19, torna-se imperativo ao debate da formação profissional dos assistentes sociais e a compreensão dos desafios postos à profissão. 
SILVA, E. C.

Efeitos da precarização em marcha no ensino superior brasileiro e os reflexos na formação profissional em Serviço Social

\section{PRECARIZAÇÃO EM MARCHA NO ENSINO SUPERIOR}

A precarização do ensino superior público é um quadro que assusta e que não dá para ignorar: faltam professores, infraestrutura adequada, recursos para a pesquisa, livros em boas condições e atualizados, faltam vagas, incentivo à pesquisa e autonomia universitária. A lógica neoliberal que afeta o Estado brasileiro e que foi intensificada no governo Bolsonaro adentra o espaço universitário, estimulando também a privatização do ensino e promovendo a sua desqualificação.

Lima e Cassab (2002, p.77-78) sinalizam que não se pode esquecer que o ensino superior na América Latina vem sendo historicamente pensado, formulado e efetivado "a partir das exigências do padrão de acumulação do capital". Portanto, a política de educação em nível superior "está inscrita no contexto do reordenamento internacional do capitalismo em sua fase atual", ou seja, a partir da lógica de reestruturação produtiva do mundo do trabalho, o que altera radicalmente as bases do trabalho, as requisições e exigências feitas aos trabalhadores e o sentido da educação, que passa a ser para atender estes critérios de acumulação do capital.

Pilares fundantes deste reordenamento do capital, que refletem diretamente na politica educacional são: a conhecida "reforma do estado2"; o infindável crescimento da divida externa; as famosas politicas de ajustes estrutural dos Organismos Internacionais 3 ; o "suntuoso" regime de acumulação financeira; a "ilustre" globalização econômica; a "famigerada" reestruturação produtiva e flexibilização do mundo do trabalho; as inacabáveis inovações tecnológicas que alteram o nível de qualificação profissional dos trabalhadores; os "novos" discursos neoliberais e de liberalização financeira, de boa governança, de cooperação internacional, de "participação cidadã", da "ética da solidariedade e do voluntariado"; os "múltiplos" critérios de racionalidade do mercado,

\footnotetext{
2 A Reforma do Estado é a adequação da estrutura do Estado às exigências do capital financeiro mundializado. Neste processo alguns traços foram evidentes e essenciais para justificar a mudança e a instituição do novo: a ideia de satanização e incompetência do Estado, o discurso da necessidade de globalização da nação, e a imagem de desqualificação de tudo o que é público, o que resultou num clima ideológico favorável a quebra de resistências politico-sociais e instituição hegemônica do capital financeiro, de ajustes econômicos, de estabilidade monetária, de privatização e de reforma do Estado. (NETTO, 2000)

3 Fundo Monetário Internacional, o Banco Mundial e Banco Interamericano de Desenvolvimento fazem parte do rol dos Organismos Internacionais que influenciam as elites nacionais (com interesses similares) a desenvolverem políticas de ajustes em vários setores, como a econômica, social e educacional.
} 
SILVA, E. C.

Efeitos da precarização em marcha no ensino superior brasileiro e os reflexos na formação profissional em Serviço Social

como a flexibilidade, competitividade, produtividade e rentabilidade; além da grosseira imagem da educação como mercadoria. (LIMA; CASSAB, 2002)

As politicas de desenvolvimento/crescimento e aceleração econômica dos países subdesenvolvidos, que "visam" a redução da pobreza, estabilidade e retomada do crescimento, utilizam a educação como elemento e instrumento essencial de "aumento do capital humano e físico dos pobres" a fim de potencializá-los para o "proveito das oportunidades econômicas", estimulando o consumo e movimentando o mercado. A utilizam também como "autoproteção", pois é a educação que pode "reduzir a probabilidade de engrossar as fileiras do desemprego, numa clara alusão ao discurso da empregabilidade ${ }^{4 "}$ (LIMA; CASSAB, 2002, P.81)

Segundo Lima e Cassab (2002, p.81-82) o papel ardiloso das reformas na política educacional "está atrelado à imperiosa necessidade de estabilidade econômica." Está pensada, nesta lógica, "na perspectiva de integração de cada país e de cada indivíduo na dinâmica do global, reafirmando as relações entre processo produtivo e formação profissional", onde o ensino superior estará estreitamente vinculado aos interesses e ditames do capital. Assim a chamada "universalização" do ensino fica restrita à ideia de "acesso à educação para todos", o que não é a mesma coisa. Na perspectiva de acesso à educação para todos, entram com todo vigor as ideias de diversificação das instituições (ou organizações) de ensino, conforme recomenda o Banco Mundial, através de universidades públicas, privadas, dos cursos politécnicos, dos cursos sequenciais, da educação à distância e dos cursos profissionalizantes de curta duração. O que predomina, sem dúvida, é o privado e a perda da qualidade do ensino superior.

Como bem destaca lamamoto (2000, p.35) "a mais ampla e profunda reforma do ensino superior no Brasil, após a ditadura, tem seu arcabouço legal na polêmica Lei de Diretrizes e Bases da Educação Nacional - Lei 9.394 de 20/12/1996". A partir de sua

\footnotetext{
4 conceito de empregabilidade "refere-se às condições individuais de competência e aptidão para: chegar ao mercado de trabalho, manter-se no emprego e reingressar no mercado de trabalho. Associase à qualificação profissional tendo como meio seguro (e visto como único) de manter-se apto, a formação profissional em bases contínuas. A educação permanente seria a estratégia possivel de salvaguardar a capacidade de transitar em um mercado de trabalho hipercompetitivo e em constante mutação. O conceito tem pressupostos, de que obter ou não um emprego depende da vontade e aptidão individual; a educação. por sua vez, adquire um caráter pragmático e reducionista de simples adequação ao mercado". (KOIKE, 1999. p.105)
} 
SILVA, E. C.

Efeitos da precarização em marcha no ensino superior brasileiro e os reflexos na formação profissional em Serviço Social

regulamentação é possivel reconhecer profundas e radicais alterações na política educacional brasileira, principalmente no ensino superior.

A elaboração, regulamentação e implementação da LDB5 "expressa a correlação de forças políticas no âmbito das relações entre o Estado e a sociedade no país, no marco das "políticas de ajuste" de raiz neoliberal, preconizadas pelos organismos internacionais". (IAMAMOTO, 2000, p.35) Ou seja, traduz, incorpora e viabiliza toda uma lógica de reformas e desmontes no ensino superior.

A regulamentação da LDB tem se dado por meio de um acervo de medidas legais, originárias do Executivo, e, mais especificamente, do Ministério da Educação e do Desporto (MEC) e de seu órgão assessor. o Conselho Nacional de Educação (CNE). Materializa-se em um conjunto de iniciativas e de instrumentos jurídicos - leis, medidas provisórias, decretos, emendas constitucionais, resoluções e pareceres -, que, silenciosamente, vem realizando uma verdadeira reforma da universidade brasileira. Ou melhor, vem criando as bases para a disseminação de um outro projeto de universidade, parametrado pelas leis de mercado e critérios de avaliação a eles atinentes, em luta com o padrão historicamente instituído na universidade brasileira, inspirado em modelos europeus. (IAMAMOTO, 2000, p.36)

Ou seja, modela um novo tipo de ensino e de universidade, pactuado com os critérios do capital, com as leis de ajuste econômico, com os ditames neoliberais, com o novo perfil de profissional que atenda as exigências de um mercado de trabalho mais flexibilizado e reestruturado. Um modelo que forma mão de obra especializada, que deteriora a qualidade do ensino, arruína com a cultura da investigação e desconstrói a autonomia da universidade enquanto espaço vital de construção de saberes, de articulação entre ensino, pesquisa e extensão, de disseminação artística, cultural, intelectual, que promove debates, conflitos, questionamentos, que impulsiona 0

\footnotetext{
5 De acordo com Ivanete Boschetti Ferreira (2000, p.82) a LDB "vem instituindo inovações no ensino superior que podem provocar profundas alterações na formação e no exercicio das profissões de nivel superior de modo geral, e na profissão de assistente social, de modo mais especifico. A perspectiva de flexibilização dos processos de formação e de exercício profissionais atinge a espinha dorsal do ensino superior com a introdução de uma série de medidas lexame nacional de curso, mestrados profissionalizantes, substituição dos currículos mínimos por diretrizes curriculares, cursos sequenciais, ensino da graduação à distâncial que impactam diretamente na concepção de profissional que se quer formar. (...) Trata-se de uma mudança na filosofia mesma do significado e papel da educação na construção da sociedade. Uma educação menos comprometida com a formação cidadã e mais voltada para os interesses do mercado, uma educação garantida mais como serviço privado e menos como direito social. Trata-se, enfim, de uma inversão nos propósitos educacionais de construção de cidadania."
}

Serviço Social em Perspectiva. Montes Claros (MG), volume 5. número 2. jul./dez. 2021. ISSN 2527-1849 
SILVA, E. C.

Efeitos da precarização em marcha no ensino superior brasileiro e os reflexos na formação profissional em Serviço Social

desenvolvimento do patrimônio científico construido e acumulado e que investe na defesa da igualdade e da democracia.

Para José Paulo Netto (2000, p.27-28), a política de ensino superior brasileira apresenta alguns traços fundamentais, que pactuam com o movimento político de reforma do Estado, são eles: a "acelerada expansão do privatismo", transformando o ensino superior em área de investimento do capital; a "liquidação" da relação ensino, pesquisa e extensão, onde o papel da pesquisa fica restrito, em muitas vezes, a institutos e centros específicos; a "supressão do caráter universalista da universidade" em detrimento da ideia de acesso a vagas para todos; a "subordinação dos objetivos universitários às demandas do mercado", dando legitimidade e eficácia mercadológica a vida universitária; e por fim, da "redução do grau de autonomia universitária", que fica restrita aos ditames do capital, restrita às verbas de custeio, e reduzida à autonomia financeira.

A exemplo disto, pode-se destacar o crescimento das fundações de direito privado dentro das universidades; o Projeto de Lei n.o 876/2015, que institui o Programa Escola Sem Partido (contra doutrinações ideológicas e emancipatórias nas escolas e totalmente partidário); a Ementa Constitucional 95 (2016) que congela os gastos públicos em saúde e educação por duas décadas, e que, ao limitar drasticamente o orçamento, impacta diretamente na autonomia universitária, na infra-estrura destas instituições (acesso e permanência), e também no desenvolvimento de pesquisas e na produção do conhecimento (articulação entre ensino, pesquisa e extensão) de qualidade.

A liberdade de cátedra também vem sendo fortemente ameaçada em consonância com a autonomia universitária: em 07 de fevereiro 2021. o Ministério da Educação (MEC) encaminhou o ofício circular n.o 4/2021/ DIFES/ SESU/SESU-MEC em que solicita a tomada de providências com o objetivo de "prevenir e punir atos políticopartidários nas instituições públicas federais de ensino", ou seja, cerceando o direito de liberdade, de comunicação, expressão e de posicionamentos ético-politicos divergentes do governo, num aprofundamento da censura e do controle. No que concerne a autonomia universitária, pode-se exemplificar os interventores indicados pelo presidente Jair Bolsonaro, por meio do MEC, para assumir as reitorias das universidades, de maneira a não respeitar o processo de escolha e autonomia das instituições, evidenciando a 
SILVA, E. C.

Efeitos da precarização em marcha no ensino superior brasileiro e os reflexos na formação profissional em Serviço Social

situações antidemocrática vivenciada nas universidades. (BRASIL, Ofício Circular n. 4/2021/ DIFES/ SESU/SESU-MEC)

De acordo com o Ministério da Educação, embasado no Projeto de Lei Orçamentário de 2021, o corte da Educação para o ano de 2021, é de 18\%, ou seja, cerca de R\$ 4,2 bilhões no orçamento, sendo que, nas universidades e institutos federais o corte chega a RS 1 bilhão, sem incluir as despesas obrigatórias, como despesas de pessoal. A Associação Nacional de Dirigentes das Instituições Federais de Ensino Superior (Andifes) alega que não há reajuste do repasse para as universidades desde 2017. (RBA. Rede Brasil Atual.2020)

Pensando em um cenário pós- pandemia, de retorno presencial, onde o investimento em infraestrutura, adequações sanitárias deveriam ser maiores, já que com as aulas online e o trabalho home-office boa parte do orçamento com água, luz, telefone foi contida e bancada pelos trabalhadores, o orçamento achatado proposto simplesmente não fecha.

Paralelo há o corte de bolsas e o incentivo a pesquisa cientifica em um cenário onde a ciência e a saúde são essenciais. Com a Portaria 34, publicada no Diário Oficial da União em 18 de março de 2020, que altera os critérios de distribuições de bolsas de mestrado e doutorado, a Coordenação de Aperfeiçoamento de Pessoal de Nivel Superior (Capes) cortou cerca de 35\% nas quantidades de bolsas de pós-graduação. Segundo a Andifes "somente em 2019, mais de 12 mil bolsas de mestrado e doutorado foram extintas. No ano passado, o governo Bolsonaro cortou $87 \%$ do orçamento do CNPq e $50 \%$ do orçamento da Capes previstos para 2020". (ANDES, 2020)

Paralelamente está sendo aprovada uma proposta de Emenda à Constituição 186/2019 (Emenda Constitucional 109/2021), conhecida como PEC Emergencial, que prevê nada menos que um grande arrocho salarial nas contas públicas, em um ataque direto ao serviço público, com o congelamento de aumento salarial e progressões por quinze anos, além do impedimento de concursos públicos. Ou seja, institui ajuste fiscal nas costas do serviço público alegando que com esta medida poderá arcar com o Auxílio Emergencial (Lei 13.982/20) - auxílio financeiro concedido em decorrência da pandemia - e que, com esta medida, o governo contará com 44 bilhões do orçamento para manter o auxílio. numa jogada política de mestre extremamente oportunista para atacar os trabalhadores. 
SILVA, E. C.

Efeitos da precarização em marcha no ensino superior brasileiro e os reflexos na formação profissional em Serviço Social

Portanto é uma politica de desmonte dos direitos sociais e de ajuste fiscal determinada por organismos internacionais que levam ao sucateamento e deterioração da educação, que estimula a ampliação do ensino particular em detrimento do ensino público, reduz consideravelmente a educação pública e fortalece a mercantilização do ensino mais curto, com formações mais rápidas e menos densas; de expansão e diversificação do sistema de ensino superior, que em parte atende à demanda de vagas ofertadas, mas que leva a flexibilização do ensino e privilegia a quantidade em detrimento da qualidade; de esvaziamento da universidade enquanto instituição de interesse público, como espaço de criação de novos saberes e construção do conhecimento; e por fim, de mudança no perfil das universidades e da educação brasileira, dando-lhe um sentido de serviço a ser explorado e vendido. (FERREIRA, 2000) As diversas fontes de financiamento das universidades instituem taxas acadêmicas, cobrança de matrículas, instituição de mensalidades, redução de verbas ou estabelecimento de critérios de elegibilidade para a concessão de apoio e incentivo a pesquisa. O espaço público passa a ser utilizado para fins privados, onde as áreas de maior interesse para o capital acabam recebendo mais estímulos e recursos para a pesquisa do que as áreas que não atendem direta ou exclusivamente aos interesses do mercado, como as ciências humanas e aplicadas. A construção do conhecimento fica abalada pelos interesses do mercado, o que compromete a sua liberdade e autonomia.

\begin{abstract}
A chamada política educacional tem sido a política do corte das verbas públicas para a educação e especificamente para a educação superior. A alocação destas já escassas verbas é feita tanto para as universidades públicas como para as universidades privadas - tratadas num mesmo patamar e estaria condicionada a um processo de avaliação institucional constituido a partir da lógica empresarial custo/benefício e da produtividade de cada universidade, entendida nos parâmetros de adequação da formação profissional a partir das exigências do capital. (LIMA; CASSAB, 2002, p.83-84)
\end{abstract}

A universidade pública passa a ser utilizada para fins privados, é submetida à lógica empresarial e do mercado financeiro, sendo fortemente descaracterizada e flexibilizada. Esta, perde sua autonomia, tendo, muitas vezes, que adaptar seus currículos de graduação e pós-graduação às demandas do capital. Sua qualidade de ensino, pesquisa e extensão é tensionada e atingida por critérios de produtividade e rentabilidade econômica.

Serviço Social em Perspectiva. Montes Claros (MG), volume 5. número 2. jul./dez. 2021. ISSN 2527-1849 
SILVA, E. C.

Efeitos da precarização em marcha no ensino superior brasileiro e os reflexos na formação profissional em Serviço Social

Marilena Chauí em seu artigo "O mal-estar na universidade: o caso das humanidades e das ciências sociais" (2001, p.157) discute a situação do ensino e da pesquisa mais precisamente nas ciências humanas e sociais, expondo "o mal-estar que perpassa e corrói" as universidades brasileiras e da América Latina com relação a estas áreas do conhecimento.

A autora apresenta três conjuntos principais de preocupações que assolam as entidades de ensino, segundo o Simpósio Internacional Humanidades, Pesquisa, Universidade, realizado em 1994 pela Faculdade de Filosofia, Letras e Ciências Humanas da USP. Segundo Chauí (2001, p.158) estes elementos cruciais e perturbadores são:

1. $\bigcirc$ "lugar, papel e sentido da universidade, em geral, e das humanidades e ciências sociais" na contemporaneidade, influenciadas e atingidas pela ideologia neoliberal e pelo capital. Essa preocupação está baseada nos novos sentidos e papéis atribuidos às universidades e à atuação do mercado em seu interior, com a valorização das áreas que proporcionam mais rentabilidade econômica ao capital;

2. $\bigcirc$ "estado da arte", a partir das "crises e impasses científicos do ponto de vista da definição dos campos de investigação, de métodos e técnicas de pesquisa, de relações com outras ciências", bem como as formas de interdisciplinaridade. objetos de investigação, conceitos, valores e finalidades que são "atribuídos às investigações". Esta observação demonstra como as mudanças no sentido da educação adentram e afetam a construção do saber e sua relação com as diversas áreas do conhecimento:

3. Os "problemas na formação de pesquisadores", a partir da crítica de uma formação "individualizada e aleatória", da relação pouco definida entre ensino e pesquisa, dos "modelos de trabalho" que separam estes saberes, do "excesso de especialização e de fragmentação de pesquisas" e do processo de formação baseado em "receitas e rotinas que bloqueiam a originalidade e a criatividade" e a inovação do saber. Por último, esta análise problematiza como estas reformas e desmontes do sistema educacional afetam a prática de pesquisas e a própria formação de profissionais aliada ao processo de construção e reconstrução do conhecimento. 
SILVA, E. C.

Efeitos da precarização em marcha no ensino superior brasileiro e os reflexos na formação profissional em Serviço Social

Além destes elementos, Chauí (2001, p.159) aponta como constantes preocupações a gritante diferença entre a pesquisa de caráter público e a pesquisa de caráter privado; a privatização como determinante para escolhas de critérios, objetivos, resultados e beneficios de algumas áreas nas pesquisas; a abalada relação entre as ciências humanas e sociais com as novas tecnologias e ciências aplicadas; o "peso das estruturas administrativas e burocráticas sobre a docência e a pesquisa, submetendo-se a uma lógica que thes é contrária e que as impede de realizarem-se plenamente", numa pressão constante de produção e rentabilidade; a ausência ou lacuna de um projeto acadêmico e de uma política universitária especifica para a pesquisa; e a "desaparição da própria necessidade social" do campo das ciências humanas e sociais; dentre outras observações.

Como se observa, não somente a universidade e a educação perdem seu sentido. mas as próprias ciências humanas e sociais passam por este processo, por esta perda de significados e essência. Para Chauí (2001. p.161) esta "inessencialidade" foi produzida historicamente por três etapas, quais sejam:

1. Primeira Etapa: 1964-1974 - "nossa inessencialidade apareceu sob a imagem do perigo subversivo. Éramos inessenciais para um projeto político do qual surgíamos como adversários: o projeto de "integrar a nação à modernidade capitalista". O pensar, analisar, discutir, problematizar o novo, o instituido, as reais intenções de um novo projeto de mudança é visto como uma ameaça;

2. Segunda Etapa: 1974-1985 - "fomos declarados inessenciais porque já estava implantado o projeto universitário da ditadura ou do "milagre brasileiro", isto é, o desmantelamento do ensino público", além da "ampliação de escolas privadas", das reformas curriculares, da criação dos cursos profissionalizantes, da diminuição do direito ao acesso à universidade pública, além da redução das verbas e recursos para educação. Nesta conjuntura ocorre a crise mundial do capitalismo, denominada "crise do petróleo" que determinou o fracasso do "milagre" que "vivenciava" ou buscava o país e que abriu às portas ao neoliberalismo;

3. Terceira Etapa: inicia-se em 1985 e segue até os dias atuais - resume-se na "falência universitária das humanas, postas como improdutivas, corporativas, rotineiras, irrelevantes". Simultaneamente, esta inessencialidade vai surgindo "pelas condições materiais da sociedade brasileira, isto é. sua entrada na chamada 
SILVA, E. C.

Efeitos da precarização em marcha no ensino superior brasileiro e os reflexos na formação profissional em Serviço Social

"acumulação flexivel do capital", ou "desregulamentação econômica", e pela adoção da ideologia neoliberal", materializados na globalização, fragmentação e dispersão do saber, e na "crise dos paradigmas". O falso discurso da modernidade adentra o espaço do conhecimento e disfarçado é tido como salvação, mágica, milagre que enfrentará esta crise. (CHAUÍ, 2001, p.164-165)

Portanto os critérios de qualidade são definidos pelo mercado, e é ele quem passa a regular a vida acadêmica, tornando a pesquisa, a investigação e as ciências humanas e sociais descartáveis ou, nas palavras de Chauí (2001) "inessenciais". A universidade passa a ser a universidade de serviços, a pesquisa aquela que visa estritamente resultados e o conhecimento aquele que é transformado e coisificado em forças econômicas produtivas.

A partir das perspectivas apresentadas, é possivel perceber que há sem dúvida um estímulo a privatização do ensino público e uma responsabilização do indivíduo pela sua formação, condicionada a "aquisição" de competências e habilidades para atuar num mercado altamente competitivo e desigual. É neste quadro que há de se pensar a formação em Serviço Social, tanto pelas dificuldades que as universidades públicas vêm enfrentando, quanto pelo acelerado crescimento privado de cursos de Serviço Social, presencial ou à distância, que muitas vezes estão desconectados com o projeto profissional do Serviço Social e aliados ao projeto hegemônico do capital, agravados por um contexto de pandemia que estimula o ensino remoto. Estes cursos, em grande parcela, não estão vinculados a ABEPSS, não estão sendo apoiados pelo conjunto CFESS/CRESS (como é o caso dos cursos de graduação à distância), e não estão a par dos encontros, oficinas, debates sobre formação profissional e das diretrizes curriculares, - que empobrece suas propostas de ensino, totalmente deslocadas com os avanços e reformas da categoria.

Em outro viés de análise, estão os estudantes e suas condições concretas de vida e acesso à educação. Uma grande parcela dos graduandos e pós-graduandos em Serviço Social precisam se inserir no mercado de trabalho para poder sobreviver, manter os estudos ou adquirir seu passaporte para a formação superior ou continuada. Trabalhar e estudar é a realidade da maioria, que infelizmente sacrificam seus estudos e oportunidades de aperfeiçoamento profissional em detrimento do salário no fim do mês. 
SILVA, E. C.

Efeitos da precarização em marcha no ensino superior brasileiro e os reflexos na formação profissional em Serviço Social

Um perfil de estudantes que deve ser pensando em todo o currículo, pois são estes estudantes que vivenciam na pele a luta pela sobrevivência, os anseios da classe trabalhadora, e a realidade nua e crua do capital.

E todos estes elementos incidem diretamente no processo de formação profissional, através de currículos que sofreram profundas reformas e flexibilizações a fim de considerar todas estas alterações e transformações que sofrem as universidades, os estudantes, os usuários dos serviços prestados e a própria profissão como um todo. Como já mencionado, nem sempre é possível seguir o que orienta as diretrizes gerais para o curso de Serviço Social por conta dessa correlação de forças, contradições de propostas e interesses, por conta da precariedade da educação, e também, devido a uma desarticulação entre as múltiplas unidades de ensino. Na Pós-Graduação entram os Mestrados Profissionalizantes, voltados muito mais para o mercado do que para a qualificação acadêmica, sem contar na redução do tempo para a conclusão dos Mestrados e Doutorados. Nesta lógica alteram-se também os projetos pedagógicos, que também sofrem com a flexibilização e redução de conteúdos. A pesquisa perde o seu sentido original e vem sendo reconfigurada de acordo com as exigências do capital.

OS IMPACTOS DO DESMONTE DAS UNIVERSIDADES NA FORMAÇÃO PROFISSIONAL DO SERVIÇO SOCIAL

As diretrizes curriculares do Serviço Social, após anos de debates e avanços, articuladas com o projeto ético-político e o aparato legal da profissão, bem como os projetos político-pedagógicos dos Mestrados e Doutorados visam uma formação crítica, reflexiva, propositiva, de transformação e emancipação, tem sido fortemente abalados com a influência do Estado em uma formação voltada aos interesses do capital. Essa realidade rebate diretamente no saber e na ação profissional do Serviço Social, que. muitas vezes, pode ficar sujeita à ditadura do mercado.

Apesar do significativo avanço teórico e metodológico alcançado pela profissão, a dimensão investigativa e a inserção na pesquisa, com o objetivo de construir conhecimento, é um desafio para a profissão. A formação profissional, influenciada por variados fatores, como a privatização das universidades, a qualidade do ensino, falta de apoio à produção científica, deficiências nas condições de trabalho dos docentes, tempo 
SILVA, E. C.

Efeitos da precarização em marcha no ensino superior brasileiro e os reflexos na formação profissional em Serviço Social

de dedicação insuficientes, ausência de estímulo às capacitações e dificuldades no desenvolvimento de pesquisas, tem se delimitado a um "ensino formal que não consegue explicar e acompanhar a dinâmica da realidade social". (DE CARVALHO, A. M. P.: BONETTI, D. A., IAMAMOTO, M. V., 1984, p. 133)

Segundo Ammann (1984, p.149), "não pode haver produção científica e teórica sem uma organização que a suporte e sustente". As universidades, desta forma, tanto no nível de graduação, quanto de pós-graduação, com os programas de mestrado e doutorado, têm contribuido significativamente com o que vêm sendo produzido dentro da profissão, pois se apresentam como um terreno mais fecundo para a prática da pesquisa e o debate teórico. Monografias, dissertações, teses e relatórios são pesos importantes na produção do conhecimento e foram "responsáveis pela quase absoluta maioria dos livros publicados (...) por autores brasileiros no domínio do Serviço Social". (AMMANN, 1984, p.155)

"No Brasil, a pós-graduação é oficialmente implantada em 1972, pelas Pontifícias
Universidades Católicas do Rio de Janeiro e de São Paulo. Desde 1966, a
Universidade Federal do Rio de Janeiro oferecia cursos de aperfeiçoamento e
especialização, cujos alunos procediam em grande parte dos quadros docentes
das universidades brasileiras. Esses cursos, bem como o Centro de Planejamento
Social da PUC-RJ e a crescente exigência qualitativa quanto às monografias
obrigatórias para a conclusão do bacharelado, reforçados pelo movimento de
reconceituação da profissão, constituem-se em fatores vigorosos de estímulo
ao desenvolvimento do espírito da pesquisa e da produção de conhecimentos
no âmbito do Serviço Social. As pós-graduações vêm, assim, ao encontro de
necessidades e exigências geradas não só na esfera acadêmica, como também
no espaço das instituições e da conjuntura nacional." (AMMANN, 1984, p.157)

A pesquisa "A Formação Profissional do Assistente Social: Determinantes Históricos e Perspectivas", elaborada em 1984, num momento de revisão curricular, já encarava o problema da investigação, "explicitando suas relações com o contexto universitário e com a prática profissional". Ressaltava em suas justificativas que a complexidade e diversidade da formação profissional "supõe um balanço crítico do atual estágio de qualificação técnico-científica deste profissional na sociedade brasileira", indicando a importância de resgatar direções e perspectivas que estão impressas no processo de formação profissional, destacando elementos da relação pedagógica e da relação prática. (DE CARVALHO, A. M. P.: BONETTI, D. A., IAMAMOTO, M. V.. 1984, p. 107108) 
SILVA, E. C.

Efeitos da precarização em marcha no ensino superior brasileiro e os reflexos na formação profissional em Serviço Social

As autoras complementam, afirmando que:

\begin{abstract}
"A análise sobre a formação profissional do assistente social hoje, insere-se no debate sobre a realidade do ensino superior na universidade brasileira e é indissociável da análise do papel e significado da profissão de Serviço Social frente às forças sociais presentes na sociedade, como atividade inscrita na divisão social do trabalho. Supõe estabelecer uma estreita articulação entre prática e formação profissional. Neste sentido, busca-se apreender a profissão como atividade historicamente determinada pela maneira como se organiza a sociedade e, ao mesmo tempo, como resultado da atuação da categoria profissional, isto é dos posicionamentos e respostas por ela imprimidos às demandas sociais dos diferentes grupos e classes sociais". (DE CARVALHO, A. M. P.; BONETTI, D. A., IAMAMOTO, M. V., 1984, p. 108)
\end{abstract}

Nesta pesquisa, desenvolvida na década de 80 , é problematizado o processo de formação profissional dos assistentes sociais enquanto um movimento historicamente situado, que deve considerar as dimensões de um projeto educacional - docência teórico-prática, pesquisa e extensão - dentro do contexto da universidade brasileira, numa relação íntima com a prática profissional pautada na realidade social.

Deve-se considerar que as dificuldades enfrentadas no fim dos anos 70 , início dos $80^{6}$, como a inflação, redução salarial, desemprego estrutural, crise bancária, explosão do endividamento público, privatizações, ditadura militar, sucateamento do setor público e início da agenda neoliberal, afetam diretamente a classe trabalhadora, através de um empobrecimento generalizado e crise dos serviços sociais públicos. Há um requestionamento no interior da profissão acerca da função social e significado político da ação do assistente social no contexto das relações sociais.

É dentro deste contexto, que se iniciou uma discussão significativa sobre formação profissional associada às novas exigências da sociedade brasileira, onde foram questionados critérios de qualidade, a possibilidade de uma formação mais especializada. além de uma problematização acerca do direcionamento dado ao processo de ensino,

\footnotetext{
6 Segundo lamamoto (2010, p. 211) "O crescimento econômico é impulsionado pelo grande capital monopolista com o forte apoio das politicas governamentais e do aparato coercitivo do Estado. (...) $O$ forte arrocho salarial sobre o conjunto dos trabalhadores; a abolição prática do direito de greve; a substituição do regime de estabilidade no trabalho pelo Fundo de Garantia por Tempo de Serviço (FGTS); o cerceamento dos sindicatos dos trabalhadores; o banimento de partidos politicos, acompanhado de restrições aos direitos civis e políticos impulsionam o aumento da produtividade e a extensão da jornada de trabalho que se encontra na base da superexploração do trabalho e do crescimento do fosso das desigualdades sociais."
} 
SILVA, E. C.

Efeitos da precarização em marcha no ensino superior brasileiro e os reflexos na formação profissional em Serviço Social

seus objetivos e conteúdos, destacando a importância do processo teórico, de formação profissional, para o desenvolvimento de uma prática consciente. Ou seja, estabelece-se uma discussão acerca de formação e exercicio profissional, de teoria e prática. E não só uma prática comum, mas uma prática carregada de consciência teórica, ou seja, aquela que consegue aplicar na prática o ensino da teoria.

Nesta conjuntura, inicia-se um debate sobre o contexto da universidade pública brasileira, onde se origina o processo de formação profissional dos assistentes sociais, de forma a compreender que o quadro geral vivenciado nas universidades afeta diretamente a formação destes profissionais.

Na pesquisa supracitada, as autoras compartilham desta interpretação e acreditam que a análise da formação precisa ser vinculada à análise da situação da universidade. pois os problemas que assolam a instituição afetam também o ensino, a pesquisa e a extensão dos cursos, ou seja, afetam a formação destes profissionais. Ao formar mãode-obra, ao preparar para o mercado de trabalho, ao apenas reproduzir conhecimento sem gerar debates, análises e discussões, a universidade pode estar apenas preparando para o emprego e não alcançando uma formação técnica, científica, crítica de profissionais conscientes, capazes de superar as demandas presentes em sua realidade de trabalho e produzir conhecimento, aptos para traçar estratégias e criar alternativas no enfrentamento das expressões da questão social.

Em um cenário de pandemia provocado pelo novo Coronavírus que atingiu o mundo a partir de 2020, os impactos no processo de formação são ainda maiores. Embora o vírus não escolha classe, etnia ou gênero, as condições de vida destes sujeitos determinam quais estarão com mais possibilidades de sobreviver, e, aos estudantes, não evadirem em decorrência do agravamento das expressões da questão social. A Educação já vinha sendo fortemente atacada, mas com a Covid-19 a crise já instaurada se intensifica a partir das seguintes evidências:

1. Inacessibilidade a tecnologias educacionais: a interação e metodologia do ensino remoto fica comprometida na medida que, boa parcela dos estudantes possuem pacotes de dados limitados para o uso da internet, ou, simplesmente não possuem. Muitos não possuem os equipamentos adequados (computadores, 
SILVA, E. C.

Efeitos da precarização em marcha no ensino superior brasileiro e os reflexos na formação profissional em Serviço Social

webcams, fones), softwares mais recentes, e o próprio conhecimento indispensável para acessar plataformas e ambientes digitais (inclusão digital). No ambiente presencial havia disponivel laboratórios e recursos para quem necessitava, mesmo que de forma parcial ou limitada. Este cenário aponta para Programas de Inclusão Digital ofertados via assistência estudantil com o PNAS - Politica Nacional de Assistência Social, que, muitas vezes restritivos, não atendem a todos que necessitam. Isso intensifica o quadro de desigualdade de acesso e de precarização da educação;

2. Oportunismo evidente: a lógica intervencionista e mercadológica do Estado tem aproveitado o quadro de saúde pública para experenciar o ensino hibrido ou totalmente remoto, visando economia de gastos, precarização das condições de trabalho dos docentes, sem se preocupar com a qualidade do ensino e com as condições da formação, com a intenção de manter esta lógica remota excludente mesmo após controlada a crise de saúde;

3. Intensificação dos processos de trabalho: há um reordenamento da atuação dos assistentes sociais e docentes nos cursos de Serviço Social, que precisaram repensar suas práticas, flexibilizar seus horários de trabalho, permitindo que o trabalho alcançasse a vida privada, tendo que arcar com estes custos (telefone, internet, luz, materiais diversos). Há também uma burocratização e aumento de ações de cunho administrativo e uma intensificação da jornada de trabalho, principalmente para o gênero feminino, com a adaptação do trabalho doméstico, os cuidados com os filhos, com a familia, a casa e a profissão. Os docentes e pesquisadores também se debruçaram mais sobre os desafios impostos pela pandemia e desenvolveram projetos, grupos de estudos, articulações com movimentos sociais e profissionais (a exemplo do Comitê SUAS/SC - COVID-19: em defesa da vida!), - que resultou em diversas lives e produção do conhecimento, e inevitavelmente em uma sobrecarga de trabalho;

4. Consciência ético-politica e teórico-metodológica: $\bigcirc$ docente ao tentar conciliar o projeto ético-político profissional com o cenário de exclusão social acirrado pela pandemia e altamente intensificado pela lógica mercantil de 
SILVA, E. C.

Efeitos da precarização em marcha no ensino superior brasileiro e os reflexos na formação profissional em Serviço Social

atentados frequentes à ciência e ao conhecimento, se vê esgotado, pois procura considerar as particularidades e condições de vidas dos discentes, de tal maneira a flexibilizar o acesso ao ensino, dos conteúdos e metodologias, de forma a não acentuar as desigualdades educacionais e não concretizá-la como privilégio. Isso demanda esforços e ajustes muito difíceis para o docente adaptar, para que fuja de padronizações e que não considere as individualidades. $\bigcirc$ ensino remoto da forma emergencial que foi proposto traz uma questão estrutural de classe inegável à profissão;

5. Estágios comprometidos: o estágio supervisionado em Serviço Social fica extremamente comprometido, uma vez que a articulação e contato entre campo de estágio, supervisores acadêmicos e estagiários (alunos) é afetada de forma proporcional com o distanciamento. Muitos campos de atuação tiveram que readequar de forma radical seu processo de trabalho, o que demandou fechamento de campos de estágio, estágio totalmente online (sem a vivência do cotidiano e o contato direto com os usuários e profissionais da instituiçãol e a dificuldade de comprovação da carga horária mínima exigida:

6. Reflexo na atuação direta dos assistentes sociais: como uma bola de neve, a precarização na formação incide diretamente na atuação profissional dos assistentes sociais. Não apenas mais o ensino presencial ou o EAD, agora é necessário pensar no ensino remoto adaptado e "paliativo", que foi pensando de forma emergencial para garantir o acesso à educação, mas que não garante a permanência e o vínculo à universidade. Questões que levam a pensar: como - conteúdo esvaziado de debates e aprofundamentos refletirá na atuação profissional em um contexto de desmonte de políticas sociais, de negacionismo da ciência, de adoecimento em massa da população privada de direitos sociais básicos, de acirramento da pobreza na América Latina? Somente a investigação, a resistência da pesquisa e a articulação com os diversos atores sociais poderão responder.

A crise sanitária expõe a crise na educação superior e desmascara os ditames do capital. Apesar de desolador e desafiador, é preciso acreditar que a universidade também pode ser o palco da construção do conhecimento crítico, de resistência, 
SILVA, E. C.

Efeitos da precarização em marcha no ensino superior brasileiro e os reflexos na formação profissional em Serviço Social

denúncia, de luta, de possibilidades. "A Universidade brasileira hoje, expressando o próprio desenvolvimento das lutas sociais no Brasil, pode voltar a se colocar como espaço de resistência, armando-se dos recursos que the são próprios: a palavra, o debate, a critica, a competência". Desta maneira, é nesta mesma universidade ameaçada que se pode construir possibilidades, resistências e conhecimentos profissionais transgressores. (DE CARVALHO, A. M. P.; BONETTI, D. A., IAMAMOTO, M. V., 1984, p. 114)

\section{ALGUMAS CONSIDERAÇÕES: A PESQUISA COMO RESISTÊNCIA ANTE A COISIFICAÇÃO E MERCANTILIZAÇÃO DO CONHECIMENTO}

Ao pensar a construção social da profissão no Brasil é possivel afirmar que é devido a sua inserção na pesquisa e ao seu caráter investigativo, que o Serviço Social tem conseguido passar por reformas curriculares e vêm enfrentando, avaliando e repensando seu papel na sociedade de forma crítica. Também é devido a esse caráter de investigador que a profissão construiu um projeto ético-politico, conseguiu criar um estatuto legal que dá parâmetros à sua atuação, e tem conseguido romper com a lógica conservadora que permeava suas ações através de um processo de renovação e reconceituação profissional, e desta forma, tem avançado em termos teóricometodológicos, ético-políticos e técnico-operativos. Portanto, apesar dos condicionantes que dificultam e muitas vezes inviabilizam o avanço na formação e exercício profissional, estas conquistas profissionais mostram como a profissão pode conquistar resultados, pode progredir no conhecimento e superar suas maiores problemáticas e dificuldades.

Desta forma, a pesquisa e a investigação que não estão subordinadas aos interesses do capital possibilitam uma nova postura diante da realidade apresentada e uma nova forma de olhar a universidade - considerando-a, apesar de todos os seus problemas, "uma escola de cidadania", onde ela "inquieta, agita, subverte e faz germinar" o conhecimento. (NETTO, 2000, p.29) Ou ainda, como ressalta lamamoto (2000, p.42-43) preservar a universidade em sua essência, ou seja, uma universidade:

Que luta para integrar o ensino, a pesquisa e a extensão, assegurando sua liberdade didática, científica e administrativa para produzir e difundir conhecimentos - e realizar a sua crítica -, voltados aos interesses das grandes maiorias. Uma universidade que seja um centro de produção de ciência, de tecnologia, de cultivo das artes e das humanidades. E voltada à qualificação de 
SILVA, E. C.

Efeitos da precarização em marcha no ensino superior brasileiro e os reflexos na formação profissional em Serviço Social

profissionais com alta competência, para além das necessidades do capital e do mercado, ainda que as incorporando, ao reconhecer as necessidades e demandas do conjunto da sociedade. Universidade que cultive a razão crítica e - compromisso com valores universais, - coerente com sua função pública não limitada e submetida a interesses particulares de determinadas classes ou frações de classes, mas a serviço da coletividade. Instituição atenta aos desafios e dilemas nacionais e regionais, incorporando-os como matéria da vida acadêmica e participando da construção de respostas no âmbito de suas atribuições especificas. (lamamoto, 2000, p.42-43)

No entanto, a lógica atual, como foi apresentado, não é a da reafirmação deste tipo de universidade, mas sim a da universidade atravessada pela lógica mercantil, da universidade privatizada, que tem sua autonomia cerceada, empobrecida e distante dos interesses coletivos e de criação do saber, da universidade que busca resultados lucrativos, que incentiva a pesquisa que proporciona vantagens econômicas e que vende serviços. O capital se beneficia dos resultados de certas pesquisas e influencia, controla - investimento daquelas que lhe darão mais rentabilidade. "A universidade passa a ser um centro de produção de ciência e tecnologia filtrada pelos interesses do grande capital, em troca dos subsidios e financiamentos concedidos". (IAMAMOTO, 2000, p.44) A pesquisa se metamorfoseia, e ganha outros contornos:

O seu fim deixa de ser a descoberta da verdade histórica, a busca do saber universal, passando a ser dominada pelo "saber pragmático e instrumental". "operativo", "internacionalizado", produzido sob encomenda para que as "coisas funcionem". Faz com que a universidade, em nome da internacionalidade, perca a sua universalidade. (IAMAMOTO, 2000, p.50-51)

Evidencia-se desta forma um grau de comprometimento da função da universidade e da construção do conhecimento, que abalam e refletem o exercício profissional. Sabe-se que "o Serviço Social não é, historicamente, uma profissão de ponta na construção do saber. Sempre foi uma profissão voltada para o fazer". IVAZ, 1999. p.43) Mas, nos últimos anos, construiu outro status com relação à sua produção do conhecimento, a partir de muita luta, esforço e dedicação. No entanto, esta nova lógica educacional, de desmontes, estratégias mercadológicas e reformas impõem uma forte ameaça à profissão e até mesmo um risco de retrocesso em sua construção do conhecimento, que fica fortemente tensionada e sacudida com todo o cenário em marcha nas unidades de ensino no Brasil. 
SILVA, E. C.

Efeitos da precarização em marcha no ensino superior brasileiro e os reflexos na formação profissional em Serviço Social

Portanto, diante deste cenário e ao pensar a universidade, formação e exercício profissional em Serviço Social, é preciso destacar a importância da indissociabilidade entre ensino/pesquisa e extensão, e elevar a pesquisa como o elemento que possibilita ruptura, resistência, combate, debate, desvendamento e descoberta do novo, que dá condições de evitar este retrocesso e que potencializa e mantém a construção do saber. Uma pesquisa que seja propulsora e mola essencial do conhecimento, e não uma pesquisa que serve estritamente à lógica do mercado. Compreender a pesquisa como vínculo com a realidade, como articulação entre saber e fazer, como revelação e análise de situações concretas, como "caminho para a identificação das mediações históricas necessárias à superação da defasagem entre o discurso genérico sobre a realidade e os fenômenos singulares" e como via principal "para superar a reconhecida dicotomia entre teoria e prática", de forma a requalificar e legitimar a formação profissional. (ABESS, 1996, p.14. apud IAMAMOTO, 2000, p.71)

No entanto, essa dimensão da formação profissional que também está tensionada e abalada pela reforma universitária, necessita de alguns elementos para superar seus maiores entraves. Aqui $\bigcirc$ apoio dos núcleos de pesquisa larticulados regional e nacionalmente), projetos de extensão, estágio acadêmico, a articulação entre a graduação e pós-graduação, a interlocução entre ABEPSS, CFESS, CRESS, ENESSO (movimentos sociais, estudantis e de classe) são elementos primordiais para reforçar e fortalecer a cultura da pesquisa e superar os desafios que ela encontra juntamente com a universidade, impulsionando o debate plural, a troca de informações, o aprimoramento intelectual, o sentido de pertencimento de classe e utilizando o espaço de construção do saber acadêmico como construção e contribuição para o saber profissional, a fim de romper com a ideia de "treinamento", "adestramento", "parcialização" e "fragmentação" do ensino. "Enfim, indagar a realidade, produzir conhecimentos significativos para a sociedade e projetar ações pertinentes" para a coletividade, de maneira a defender o espaço público da universidade e amparar sua função crítica, propositora e inovadora do saber. (IAMAMOTO, 2000, p.72)

Tempos dificeis estão por vir com o agravamento das expressões da questão social e o cenário pandêmico crítico vivido no último ano colocam em evidência a importância das universidades públicas e institutos de pesquisa no enfrentamento e 
SILVA, E. C.

Efeitos da precarização em marcha no ensino superior brasileiro e os reflexos na formação profissional em Serviço Social

desvelamento de estratégias de superação desse quadro. Mesmo em um contexto de negacionismo da ciência e da pesquisa, é ela quem tem buscado soluções eficazes que trazem esperança à sobrevivência da população - mapeamento genéticos, desenvolvimento de vacinas em tempos recordes, projetos de inclusão e assistência à saúde da população. Parece utópico pensar a pesquisa com tamanha força e potência, mas é ela que indica movimento, democratização das informações e alternativas de uma sociedade mais justa e menos alienante.

Utilizar a pesquisa, sobretudo, como estratégia de resistência ao sistema que está imposto, como atitude combativa e não passiva, reafirmando a luta de classes por uma universidade pública de qualidade, aliado ao projeto ético-político profissional, rompendo com o aligeiramento do ensino, retomando sua qualificação que se deve dar através do ensino, da pesquisa e da extensão e num espaço público, democrático e crítico e como respostas às demandas postas pela realidade profissional, de maneira a preservar a essência da universidade que é a construção e reconstrução do conhecimento. Ou seja, pensar a pesquisa como uma "aventura do espírito" 7. "como uma viagem fantástica em termos de reflexão, de interrogação, de questionamento. A reflexão que interroga o que parece evidente. Uma reflexão que além de individual é, antes de tudo, uma aventura coletiva". (YAZBEK, 2005, p.148) Ou ainda, uma reflexão que é "uma prospecção do futuro", uma esperança do amanhã, um olhar sem indiferença sobre novos caminhos que alcancem a liberdade de pensamento, que possibilitem novas alternativas e novas utopias.

Neste tipo de pesquisa a indissociabilidade entre teoria/prática não pode ser uma opção, mas sim requisito fundamental de análise, porque a pesquisa exige esta articulação, esta mediação entre teoria e realidade. Neste sentido, a pesquisa é o canal que vai superar ou enfrentar com mais propriedade o grau de comprometimento da universidade, de resistência aos desmontes que a atingem, e de superação da dicotomia entre teoria e prática. $\bigcirc$ momento pandêmico exige isso, pois para preservar vidas há de se acreditar na ciência e se destacar a função social da Educação, de emancipação, de consciência ético-política e de valorização dos direitos humanos.

\footnotetext{
${ }^{7}$ De acordo com Yasbek (2005, p.148) o autor Otávio Ianni nos comentários do livro de Istiven Mészaros, em 2003, reconhece a pesquisa como uma aventura do espírito e que para ele "uma interpretação dos dados de uma pesquisa é como a elaboração de uma sinfonia: a partir da descoberta do tema... [o pesquisador] vai compondo seu trabalho, sua interpretação, suas conexões de sentido, a explicação científica, o todo que se esconde atrás do factual, a universalidade contida no singular no discreto e até no minúsculo".
} 
SILVA, E. C.

Efeitos da precarização em marcha no ensino superior brasileiro e os reflexos na formação profissional em Serviço Social

\section{REFERÊNCIAS BIBLIOGRÁFICAS}

AMMANN, Safira Bezerra. A produção científica do Serviço Social no Brasil. In: Revista Serviço Social e Sociedade n.o 14, ano V, abril de 1984, p. 144 - 176.

Bolsonaro propõe cortes na educação que neutraliza ganhos no novo Fundeb. RBA. Rede Brasil Atual. 12 de ago. de 2020. Disponivel em: $\langle$ https://www redebrasilatual.com.br/educacao/2020/08/bo/sonaro-corte-educacao/> Acesso em: 15 de mar. de 2021.

BRASIL. [Constituição (1988)]. Emenda Constitucional no 95, de 15 de dezembro de 2016. Altera o Ato das Disposições Constitucionais Transitórias, para instituir o Novo Regime Fiscal, e dá outras providências. Brasilia, DF: Presidência da República, [2016b]. Disponível em: 〈http://www.planalto.gov.br/ccivil_03/Constituicao/Emendas/Emc/emc95.htm〉 Acesso em: 18 de mar. de 2021.

BRASIL. Projeto de Lei n. $\mathbf{0} 867$, de 2015. Do Sr. Izalci. Inclui, entre as diretrizes e bases da educação nacional, o "Programa Escola Sem Partido". Disponível em: <https://www.camara.leg.br/proposicoes Web/prop_mostrarintegra: jsessionid=286B1B87D IAF 413244ADA930E17D364D.proposicoes Webl?codteor $=1317168$ E filename $=$ Avulso+-

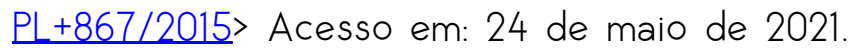

BRASIL. Ministério da Educação. Ofício Circular n.o 4/2021/ DIFES/ SESU/SESU-MEC:

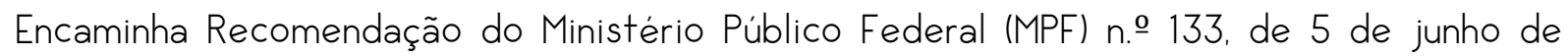
2019.

Disponivel em: <https://sei.mec.gov.br/sei/controlador_externo.php?acao=documento_conferirE_codigo_ verificador $=2483908 \varepsilon$ _codigo_crc $=4 F 00 C 798 \varepsilon$ _hash_download $=23 b 67904 b 22412 \mathrm{be} 46676 \mathrm{c}$ dc3702ed5f3fafc51e0ce352507cldebe68566570d2782ddb77939184a5604e559a01c0fc80 $\underline{b d 9570 f 8 d f c 92 b 4 b 745130031071 \text { ae } 5 \varepsilon \text { visualizacao }=1 \text { Eid_orgao_acesso_externo=0. }}$. Acesso em: 24 de maio de 2021.

BRASIL. Ministério da Educação. Projeto de Lei Orçamentário de 2021. Disponível em: $<$ https://www.gov.br/economia/pt-br/assuntos/planejamento-e orcamento/orcamento/orcamentosanuais/2021/ploa/Texto_PLOA_2021_versao_Final_PR.pdf>. Acesso em: 24 de maio de 2021.

BRASIL. Ministério da Educação. Portaria 34, publicada no Diário Oficial da União em 18 de março de 2020. Disponivel em: 〈https://wwwingovbr/en/web/dou/-/portaria-n-34de-9-de-marco-de-2020-248560278>. Acesso em: 24 de maio de 2021. 
SILVA, E. C.

Efeitos da precarização em marcha no ensino superior brasileiro e os reflexos na formação profissional em Serviço Social

BRASIL. Diário Oficial da União. Emenda Constitucional n.o 109. 16 de mar. de 2021. Disponivel em: <https://wwwingovbr/en/web/dou/-/emenda-constitucional-n-109$\underline{308527609}>$ Acesso em: 24 de maio de 2021.

BRASIL. Diário Oficial da União. Lei 13.982, de 02 de abr. de 2020. Disponível em: 〈https://www.in.gov.br/en/web/dou/-/lei-n-13.982-de-2-de-abril-de-2020-250915958 > Acesso em: 24 de maio de 2021.

CARVALHO, Denise Bomtempo Birche de. SILVA, Maria Ozanira da Silva e. (Orgs.) Serviço Social, pós-graduação e produção do conhecimento no Brasil. São Paulo: Cortez, 2005

CARVAlHO, Alba Maria Pinho de; BONETTI. Dilséa Adeodata; IAMAMOTO. Marilda Villela. Projeto de investigação: a formação profissional do assistente social no Brasil Determinantes históricos e perspectivas. In: Revista Serviço Social e Sociedade n.o 14 , ano $V$, abril de 1984, p. $104-143$.

CHAUI, Marilena de Souza. O mal-estar na universidade: o caso das humanidades e das ciências sociais. In: Escritos sobre a universidade. São Paulo: UNESP, 2001, p. 157-173.

FERREIRA, Ivanete Boschetti. Implicações da Reforma do Ensino Superior para a Formação do Assistente Social: desafios para a ABEPS. In: Revista Temporalis, ano I, no1 - Brasilia, janeiro a julho de 2000, p. 81-97.

IAMAMOTO. Marilda Villela. Reforma do Ensino Superior e Serviço Social. In: Revista Temporalis, ano I, no 1 - Brasília, janeiro a julho de 2000, p. 35 - 79.

IAMAMOTO, Marilda Villela. Serviço Social em Tempo de Capital Fetiche: capital financeiro, trabalho e questão social. 4a ed., São Paulo: Cortez, 2010.

KOIKE, Maria Marieta dos Santos. As novas exigências teóricas, metodológicas e operacionais da formação profissional na contemporaneidade. In: Capacitação em Serviço Social e Política Social: Módulo 2: Crise Contemporânea, Questão Social e Serviço Social. Brasilia: CEAD, 1999, p. 102-118.

LIMA, Katia Regina de Souza: CASSAB, Maria Aparecida Tardin. O Ensino de Graduação no Serviço Social - principais impasses e importantes potencialidades. In: Revista Temporalis, ano III, Suplemento - Brasília, novembro de 2002, p. 77-88.

NETTO, José Paulo. Reforma do Estado e Impactos no Ensino Superior. In: Revista Temporalis, ano I, no 1 - Brasilia, janeiro a julho de 2000, p. 11-33.

Portaria da CAPES corta bolsas de diversos programas de pós-graduação. ANDES. 24 de mar. de 2020. Disponivel em: 〈https://www.andes.org.br/conteudos/noticia/portaria-dacapes-corta-bolsas-de-diversos-programas-de-pos-graduacaol> Acesso em: 15 de mar. de 2021 . 
SILVA, E. C.

Efeitos da precarização em marcha no ensino superior brasileiro e os reflexos na formação profissional em Serviço Social

VAZ, Ana Lúcia. Cursos Sequenciais. A lógica do mercado invade as universidades. In: Revista Inscrita, ano II, no V. dezembro de 1999, p. 40-43.

YAZBEK, Maria Carmelita. Os Caminhos Para a Pesquisa no Serviço Social. In: Revista Temporalis, ano V, no 9 - Brasília, janeiro a junho de 2005, p. 147 - 159. 